\title{
Universalismo e o relativismo: a mutilação genital feminina e o diálogo intercultural dos direitos humanos*
}

\author{
Universalism and Relativism: Female Genital \\ Mutilation and Intercultural Dialogue on Human \\ Rights
}

\author{
Camilla Guedes Pereira Pitanga Santos** \\ José Ernesto Pimentel Filho*
}

\section{Resumo}

O presente estudo enfoca a questão da mutilação genital feminina dentro das visões do universalismo e do relativismo cultural. Como tal prática cultural pode ser compreendida ou refutada dentro da lógica dos direitos humanos e da proteção à dignidade humana? Para o desenvolvimento argumentativo, levamos em conta a hermenêutica diatópica e o diálogo intercultural. Essas ideias surgem como alternativas para um pensamento que vise buscar uma ressignificação das políticas em favor da dignidade feminina sem renunciar à identidade cultural. Isso implica na afirmação da necessidade de educação e de visibilidade relativa à violência contra à mulher.

Palavras- chave: África. Ásia. Mutilação Genital Feminina. Gênero e Direito. Educação.

\section{Abstract}

The present paper focuses on Female Genital Mutilation regarding to the debate on universalism versus cultural relativism. How does such a cultural behavior

* $\quad$ Artigo proveniente do projeto PROCAD "Espaços Democráticos Emancipadores e Inclusão: modos de efetivação de Direitos Humanos" entre a Universidade Federal da Paraíba e a Universidade de Fortaleza.

** Mestre em Ciências Jurídicas pela UFPB. Participante do projeto de pesquisa PROCAD da Pós Graduação em Ciências Jurídicas - UFPB. João Pessoa - PB - Brasil. E-mail: milapitanga@hotmail. com

*** Doutorado em História Econômica pela Universidade de São Paulo. Professor permanente do PPGCJ, UFPB. Participante do projeto de pesquisa PROCAD da Pós Graduação em Ciências Jurídicas - UFPB, além de financiamento para pesquisa de Pós-Doc por intermédio da CAPES. João Pessoa - PB - Brasil. E-mail: jpima2001@yahoo.fr 
would be understood or refused within the rationale of Human Rights and Dignity of the Human Being? In the arguments we consider the diatopical hermeneutics and the concept of intercultural dialogue. These ideas emerge as alternatives to a way of thinking with regards to seeking a redefinition of policies in favor to women dignity without giving up cultural identities. We are still affirming the women's protection which has to face the internal challenges in cultural realities where FGM is used. It does affirm the necessity of education and always put in visibility everything related to violence against women.

Keywords: Africa. Asia. FMG. Law and Gender. Education.

\section{Introdução}

Desde o século passado, com o fim da Segunda Guerra Mundial, e ainda no início deste século, com a chamada "guerra ao terrorismo", os direitos humanos estão no centro dos debates globais. Inicialmente com foco no diálogo entre Estados, o tema alcançou a sociedade civil, que, ao buscar reafirmar direitos inerentes à pessoa humana, esbarra em valores ditos culturais que cada sociedade possui. Os valores proclamados como universais desde a Declaração Universal dos Direitos Humanos (DUDH), de 1948, podem ser efetivamente implantados e aceitos por todos? A diversidade cultural pode sobrepor-se à valorização da vida em sua essência?

As culturas não possuem referenciais essencialmente similares umas com as outras e há a necessidade de uma interpretação para suprir aquilo que não se consegue igualar entre uma e outra. Pensar em realidades intocáveis ou influenciáveis é quase impossível. A aproximação proporcionada pela globalização extingue a ideia de distância e permite que as próprias identidades culturais se mesclem em um projeto que tem fortes potenciais pedagógicos, uma vez que não há mais comportamentos étnicos fixos e intocáveis frente ao diálogo cultural imperante. A relatividade dos pontos de vista culturais não está imune a processos dinâmicos de diálogo cultural constante. Conforme afirma Herrara Flores, não existe produtos culturais em si mesmo: 
[...] ni la justicia, ni la dignidad, y mucho menos los derechos humanos, proceden de esencias inmutables o metafísicas que se sitúen más allá de la acción humana por construir espacios donde desarrollar las luchas por la dignidad humana. (RÚBIO; FLORES; CARVALHO, 2010, p. 75)

Nesse contexto, exsurge a compreensão de universalismo e relativismo cultural. O relativismo opera conceitos que buscam entender ou justificar determinadas práticas localizadas. Sob o argumento da proteção, podem contraditoriamente justificar a violação dos direitos humanos.

A mulher, enquanto gênero, é sujeito - ou seria objeto? - constante na pauta dessas discussões, por vezes manipuladas, conforme a cultura em que está inserida, na qual vigorem sistemas de exclusão econômica e cultural. A prática da mutilação genital revela uma violação de seus mais inerentes direitos em nome de uma cultura de submissão a tabus de sexualidade e pressupostos patriarcais por vezes justificados em termos religiosos.

\section{A fundamentação histórica dos direitos humanos e o direito feminino}

A afirmação dos direitos humanos em discursos de qualidades distintas do plano normativo-jurídico recorre a temporalidades da religião e do mito. Nesse caso, a filosofia do direito se mescla à antropologia filosófica que considera a essência humanística das proposições em favor da afirmação da existência do gênero humano: "tudo gira em torno do homem e de sua eminente posição no mundo" (COMPARATO, 2007, p. 1) Direitos humanos são um conceito etéreo, de formulações passíveis de serem encontradas numa evolução de saberes: "A resposta a essa indagação fundamental [a questão da dignidade humana] foi dada sucessivamente, no campo da religião, da filosofia e da ciência." (COMPARATO, 2007, p. 1).

No plano histórico, consideramos os direitos humanos enquanto formulação de base iluminista contida na Declaração de Direitos da 
Virgínia (Estados Unidos), na Declaração de Direitos do Homem e do Cidadão e na Declaração de Direitos da Mulher e da Cidadã (França). A emergência dos direitos humanos das mulheres foi concorrente com os direitos do homem e do cidadão desde a origem histórica. Não se admitiu, naquele momento das revoltas parisienses em favor da primeira assembleia constituinte francesa, a existência do gênero como elemento intrínseco do direito, negando às mulheres a sua própria Declaração. Olympe de Gouges (1791) foi a autora do texto que propugnava uma autonomia do direito feminino e uma igualdade radical nos termos agudos que traz o seu preâmbulo'.

Foi entre uma das maiores expressões da historiografia marxista inglesa que surgiu um acertado ponto de vista acerca da semântica da Declaração dos Direitos do Homem e do Cidadão: "Este documento é um manifesto contra a sociedade hierárquica de privilégios da nobreza, mas não um manifesto a favor de uma sociedade democrática e igualitária." (HOBSBAWM, 1996, p. 20). O texto da Declaração de 1789 é francamente menos democrático que os termos previstos na ordem constitucional norte-americana2: "a assembleia representativa que ela vislumbrava como órgão fundamental de governo não era necessariamente uma assembleia democraticamente eleita, tampouco, no regime que estava implícito, pretendia eliminar os reis" (HOBSBAWM, 1996, p. 20).

O contexto da declaração masculina francesa se refletiu nas ideias da constituinte sustentada na Revolta da Bastilha: o garantismo das leis

\footnotetext{
Transcreve-se aqui o original: "Considérant que l'ignorance, l'oubli ou le mépris des droits de la femme, sont les seules causes des malheurs publics et de la corruption des gouvernements, ont résolu d'exposer dans une déclaration solennelle, les droits naturels inaliénables et sacrés de la femme, afin que cette déclaration, constamment présente à tous les membres du corps social, leur rappelle sans cesse leurs droits et leurs devoirs, afin que les actes du pouvoir des femmes, et ceux du pouvoir des hommes pouvant être à chaque instant comparés avec le but de toute institution politique, en soient plus respectés, afin que les réclamations des citoyennes, fondées désormais sur des principes simples et incontestables, tournent toujours au maintien de la constitution, des bonnes mœurs, et au bonheur de tous."

2 Para a realidade constitucional americana, ver Jack N. Rakove (2012) e o curso de Akhil Reed Amar sobre Constitutional Law, pela Yale, na plataforma Coursera, bem como o capítulo "A Kind of Revolution", de Howard Zinn (2005), que traz uma abordagem bastante esclarecedora acerca dos limites raciais e sociais da ordem jurídica americana de fins do século 18.
} 
e o rei no topo da sociedade. Não é o rei a expressão da masculinidade hereditária por excelência?

É assim que a Constituição de 1791 afirma sua hierarquia de funções:

Artigo $1^{\circ}$-Arealeza é indivisível, e delegada hereditariamente para a raça dominante no homem, por ordem de primogenitura, com a exclusão perpétua da mulher e sua prole. - (Nada pode ser prejulgado com efeito de renúncias na raça reinante.) Artigo 2. - A pessoa do Rei é inviolável e sagrada; seu único título é o Rei dos Franceses. Artigo 3. - Não há nada superior na França do que a autoridade da lei. O Rei reina apenas por ela, e somente em nome da lei é que ele poderá exigir obediência ${ }^{3}$. (FRANCE, 1791)

Essa declaração máscula e límpida foi pouco evidenciada até que se descobrisse que a história não é feita de interesses gerais e das oscilações do preço do pão. Ela sobreviveu ao tempo como um fato sem relevância. Ela pôde fazer-se silenciosa na imposição das obviedades aceitas de seu tempo. A tradição masculina das leis data da formação do pensamento jurídico no Ocidente, e as revoluções liberais não foram portadoras da afirmação irrestrita de direitos. As revoluções que inauguraram uma era de self government se basearam no princípio da óbvia supremacia masculina, de tal forma que se tratava de um ato inconsciente dos agentes políticos; dizemos ainda melhor se falamos de ato preconceituoso. Assim, os direitos femininos eram ignorados também na América, mais silenciados que os direitos de igualdade racial, diz de forma contundente Zinn (2005, p. 102): "Elas não estavam mencionadas na Declaração de Independência, elas estavam ausentes na Constituição, elas eram invisíveis na nova democracia política. Elas eram as mulheres da América nascente." ${ }^{4}$

3 Tradução dos autores deste artigo. Transcrição original dispensável.

4 Tradução dos autores deste artigo. Transcreve-se aqui o original: "They were not mentioned in the Declaration of Independence, they were absent in the Constitution, they were invisible in the new political democracy. They were the women of early America." 
A escravidão é outra realidade relevante para se entender o direito dos silenciados na onda dos movimentos em prol do direito escrito e da constitucionalização dos estados nacionais, o que ocorre em fins dos setecentos e nos oitocentos. A questão da escravidão foi o ponto crucial do estabelecimento da universalidade do gênero humano.

\section{Em 8 de fevereiro de 1815, as nações signatárias do Congresso} de Viena repudiaram o comércio de escravos:

Tendo em consideração: que o comércio conhecido como "o Comércio de Escravos" vem sendo considerado, por justos e esclarecidos homens de todas as idades como repugnante frente aos princípios de humanidade e moralidade universal; que circunstâncias particulares das quais o comércio tem originado, e a dificuldade de frear abruptamente seu progresso, pode ter ocultado, numa dada extensão, o que era odioso na sua continuidade, mas por fim a voz pública em todos os países civilizados clama em voz alta por sua supressão imediata; que desde que as características essenciais e os detalhes deste tráfico têm sido mais bem conhecidos, e os males de todo tipo em estágio mais avançado para o qual isso colabora, inúmeros governos europeus tem virtualmente chegado à decisão de colocar um fim nisso, e que sucessivamente todos os Metrópoles possuindo colônias em diferentes partes do mundo tem reconhecido, tanto por atos legislativos, ou por Tratados, ou outros engajamentos formais, a obrigação e necessidade de abolir isso. ${ }^{5}$

Vide Final Act of the Congress of Vienna/ Act XV. Disponível em: Acesso em: 20/07/2014. Tradução dos autores deste artigo. Transcreve-se aqui o original: "Having taken into consideration that the commerce, known by the name of "the Slave Trade," has been considered, by just and enlightened men of all ages, as repugnant to the principles of humanity and universal morality; that the particular circumstances from which this commerce has originated, and the difficulty of abruptly arresting its progress, may have concealed, to a certain extent, what was odious in its continuance, but that at length the public voice, in all civilized countries, calls aloud for its prompt suppression; that since the character and the details of this traffic have been better known, and the evils of every kind which attend it, completely developed, several European governments have virtually come to the resolution of putting a stop to it, and that successively all the Powers possessing colonies in different parts of the world have acknowledged, either by legislative Acts, or by Treaties, or other formal engagements, the duty and necessity of abolishing it." 
Observam-se alguns aspectos importantes na citação acima em termos de discurso e valores político-internacionais de época. Em primeiro lugar, trata-se de antecipar-se historicamente aos eventos da secessão americana e da supressão da escravidão no Novo Mundo, repudiando o estatuto da escravidão numa ordem monárquica europeia que se via como renascimento do espírito aristocrático de superioridade em civilização. Nesse sentido, as nações que praticavam a escravidão, o que era o caso do Brasil, seriam facilmente enquadradas como distintas daquelas ditas civilizadas, considerando o critério de distinção entre nação livre e nação escravista.

O valor da civilização como universal justificará intervenções na esfera da vigilância sobre o tráfico internacional de escravos. As consequências internacionais para o Brasil vieram a ser sentidas com o Aberdeen Act, após 1845, com o qual o Parlamento britânico foi autorizado a capturar navios negreiros em alto mar com o consentimento do imperador brasileiro.

O grande problema da escravidão estava na própria mentalidade jurídica arcaica do país, que legitimava consensualmente o ato de escravização de pessoas africanas, seu comércio e a exploração delas no Brasil. O escravo na Constituição brasileira não era cidadão. Ele não podia pegar em armas para defender o Império e, naturalmente, não era eleitor. Até 1871, a liberdade por meio da alforria podia ser revogada. 0 forro ficava juridicamente "eternamente grato" ao senhor que o libertou e a este não podia fazer ingratidão, sob pena de recair novamente na condição de escravo (COSTA, 2010).

A lei e seus tribunais imperiais no Brasil continuaram decidindo questões de forma a ignorar o reconhecimento efetivo dos direitos da pessoa humana. A interpretação dos juristas brasileiros em favor da liberdade humana inexistia. Seus arrazoados sobre o conceito de pessoa eram pífios. Longe de reconhecer os direitos naturais da pessoa humana e afirmar suas implicações inalienáveis para os direitos civis, os juristas consagravam a injustiça nos tribunais brasileiros primando por uma rule of Law baseada em práticas e teorias de países ocidentais 
(PAES, 2010). Na prática, as relações comerciais tratavam o escravo como coisa. O feto da escrava era tratado como "bem acessório" até 1871. O fim das penas cruéis proclamado na primeira carta magna brasileira, assim como os artigos versando sobre os direitos individuais, continuariam mera ficção literária.

O século XX e as duas Grandes Guerras suscitaram necessidades sobre as quais o estado jurídico ainda não havia se debruçado. A humanidade no pós-guerra clamava por reflexões profundas sobre a intolerância étnica, religiosa e de costumes e então, os contornos dos direitos humanos ganharam nova dimensão. Antes da DUDH, havia direitos humanos nacionais, o que significava que a afirmação das soberanias dos estados nacionais e a subsunção dos direitos humanos aos direitos de cidadania. Kälin e Künzli (2010, p. 6) afirmam: "os Direitos Humanos tiveram muito pouca influência sobre as relações internacionais nos séculos 18 e 19, exceto em leis de direito internacional relativas à proteção de estrangeiros". E completam: "durante este período, o princípio da soberania absoluta do Estado era um paradigma no direito internacional". 6

Mesmo a Constituição brasileira de 1988 declarou de forma insuficiente os direitos fundamentais, o que restou interpretado como equívoco redacional. Diz o caput do artigo $5^{\circ}$ da garantia "aos brasileiros e aos estrangeiros residentes no País a inviolabilidade do direito à vida, à liberdade, à igualdade, à segurança e à propriedade" quando são direitos inerentes à pessoa humana.

Nesse contexto, os direitos humanos possuem fonte recente, conforme expõe Piovesan (2012, p. 42):

Em face do regime de terror, no qual imperava a lógica da destruição e no qual as pessoas eram consideradas descartáveis, ou seja, em face do flagelo da Segunda Guerra Mundial, emerge a necessidade de reconstrução

Tradução dos autores deste artigo. Transcrição original dispensável. Desse livro, consultamos o capítulo "Origin and Universality" (KÄLIN; KÜNZLI, 2010, p. 3-30). 
do valor dos direitos humanos, como paradigma referencial ético a orientar a ordem internacional.

A quem se destinam? Qual o seu conteúdo? Quem os define? Digressões sobre o alcance dos direitos humanos são tormentas que permeiam o estado da arte na dinâmica da concretude desses direitos.

Nas palavras de Bobbio (1998), os direitos humanos não nascem todos de uma vez e nem de uma vez por todas. Para Arendt (1979), os direitos humanos não são um dado, mas um construído, uma invenção humana, em constante processo de construção e reconstrução.

Com o surgimento da Organização das Nações Unidas (ONU), em 1945, e a Declaração Universal de 1948, reiterada pela Declaração de Direitos Humanos de Viena de 1993, destaca-se a concepção contemporânea de direitos humanos, marcados pelas características da universalidade, indivisibilidade e interdependência.

Mais que em qualquer outro momento, o valor supremo da dignidade da pessoa humana foi compreendido pela sociedade das nações reunidas na ONU. A principal característica - a universalidade - funciona como paradigma moral de respeito aos direitos mais elementares do ser humano. Explica Piovesan (2012, p. 124):

Universalidade porque clama pela extensão universal dos direitos humanos, sob a crença de que a condição de pessoa é o requisito único para a titularidade de direitos, considerando o ser humano como um ser essencialmente moral, dotado de unicidade existencial e dignidade, esta como valor intrínseco à condição humana.

Ao examinar a indivisibilidade e a interdependência dos direitos humanos, leciona Espiell (1986, p. 16-17):

Só o reconhecimento integral de todos estes direitos pode assegurar a existência real de cada um deles, já que sem a efetividade de gozo dos direitos econômicos, sociais e culturais, os direitos civis e políticos se reduzem a meras categorias formais. Inversamente, sem a realidade dos direitos civis e políticos, sem a efetividade 
da liberdade entendida em seu mais amplo sentido, os direitos econômicos, sociais e culturais carecem, por sua vez, de verdadeira significação. Esta ideia da necessária integralidade, interdependência e indivisibilidade quanto ao conceito e à realidade do conteúdo dos direitos humanos, que de certa forma está implícita na Carta das Nações Unidas, se compila, se amplia e se sistematiza em 1948, na Declaração Universal de Direitos Humanos, e se reafirma definitivamente nos Pactos Universais de Direitos Humanos, aprovados pela Assembleia Geral em 1966, e em vigência desde 1976, na proclamação de Teerã de 1968 e na Resolução da Assembleia Geral, adotada em 16 de dezembro de 1977, sobre os critérios e meios para melhorar o gozo efetivo dos direitos e das liberdades fundamentais (Resolução n. 32/130).

Ora, esses argumentos legitimam a ideia de que a comunidade internacional deve ter jurisdição sobre estados nacionais, articulando um conjunto fundamental de direitos que implicam em universalidade de valores em prol dos direitos humanos. Cabe às pessoas no mundo inteiro lutarem pelo reconhecimento dos seus direitos fundamentais independentemente da positivação em leis (FLORES, 2009).

\section{Relativismo x Universalismo}

Direitos humanos e direitos fundamentais por vezes são referidos como sinônimos, pois são concebidos em torno das garantias jurídicas. A tendência doutrinária e normativa é contextualizar o termo "direitos humanos" na ordem internacional, com uma conotação prescritiva ou deontológica, relacionados a exigências básicas relacionadas à dignidade, liberdade e igualdade, enquanto os direitos fundamentais são aqueles positivados em nível interno, como fator de consolidação do princípio democrático, "tal como elemento constitutivo do estado de direito, os direitos fundamentais são um elemento básico para a realização do princípio democrático" segundo Canotilho (2003, p. 290).

Outra acepção é aquela que sinaliza no sentido de reconhecer os direitos humanos como valores multidisciplinares que transcendem 
à esfera da dogmática e da aplicação jurídica das normas, de forma a alcançar a dimensão política e outras formas de ativismo, ultrapassando a instrução formal:

Numa conjuntura de promoção e defesa dos $\mathrm{DH}$, em tempos de globalização, cabe construir práticas educativas promotoras de uma ética comprometida com a universalidade e a diversidade, com a promoção e a defesa de direitos individuais, o avanço da modernidade e a conquista dos direitos coletivos protagonizados nos processos de organização e de lutas de distintos atores sociais. Essa aproximação histórica entre distintos sujeitos sociais e institucionais, entre saberes formais e informais, práticas informais, não-formais e formais educativas, áreas de conhecimento e campos de intervenção, e múltiplas identidades étnicas, sociais e culturais, vai constituir os elementos para o exercício da transdisciplinaridade dos direitos humanos no campo educativo e cultural. Significa, em resumo, que a educação em Direitos Humanos se apresenta como um campo possível de diálogo e de conflitos, construção de consensos e dissensos, subjetividades, culturas, modos de ser e de agir, conhecimentos formais e não formais. (FEITOSA, 2009, p. 107)

Canotilho (2003) enfoca ainda o princípio da salvaguarda do núcleo essencial, segundo o qual, mesmo em casos que o legislador esteja constitucionalmente autorizado a editar normas restritivas, permanecerá vinculado à salvaguarda do núcleo essencial dos direitos, liberdades e garantias.

Nesse contexto, a positivação dos direitos humanos nos ordenamentos internos representa a integração de valores tidos por essenciais à boa convivência coletiva, oferecendo maior segurança às relações sociais. Referindo-se a feixes ideológicos, expõe Lafer (1999, p. 182-183):

A objetivação histórica do valor da pessoa humana, na relação política-jurídica governantes-governados, exprimese através da afirmação da perspectiva ex parte populi por 
meio do reconhecimento, pelo direito positivo, dos direitos humanos. Esta positivação expressa um processo histórico de integração de valores percebidos como fundamentais para a boa convivência coletiva. Provêm de legados históricos, irradiadores de feixes axiológicos configuradores de um sentido de direção.

A existência de direitos fundamentais formais, contudo, não é suficiente para garantir a tolerância entre os cidadãos que divergem entre si, em suas concepções morais e politicas, dentro ou fora de seus limites territoriais. A globalização enquanto fenômeno cultural e econômico permite a aproximação e difusão de culturas outrora distanciadas do eixo ocidental homogeneizante.

A defesa da diversidade cultural se choca com a tentativa de aplicação de um pluralismo cultural com fórmulas próprias ao conceito ocidental de Direito, e aí as teorias universalista e relativista surgem para teorizar e justificar posicionamentos.

Como é cediço, existem culturas - notadamente orientais - cujas práticas difundidas em seus limites territoriais por vezes são repugnadas veementemente pelo padrão ocidental. Mas até que ponto o paradigma ocidental pode servir à caracterização de "civilizado" e "não civilizado"?

Partindo-se do pressuposto de que diferentes culturas têm concepções variáveis de justiça e direito, transformando-se no tempoespaço, reflete Unger (1979, p. 61): "A lei regulatória não é uma característica universal. Limita-se a situações nas quais a divisão entre Estado e sociedade foi estabelecida e certas normas de comportamento assumiram a forma de prescrições, proibições ou permissões explicitas." Nesse sentido, Piovesan (2008, p. 148) afirma:

Para o relativismo, é valido todo e qualquer sistema cultural, com o argumento de que uma crença ou ação humana deve ser justificada dentro de sua própria cultura, independentemente dos direitos humanos ratificados através de tratados internacionais. As variações culturais não podem ser criticadas pelas demais, e sim respeitadas. 
Para os relativistas, a noção de direito está estritamente relacionada ao sistema politico, econômico, cultural, social e moral vigente em determinada sociedade. Sob esse prisma, cada cultura possui seu próprio discurso acerca dos direitos fundamentais, que está relacionado às específicas circunstâncias culturais e históricas de cada sociedade. Nesse sentido, acreditam os relativistas, o pluralismo cultural impede a formação de uma moral universal, tornando-se necessário que se respeitem as diferenças culturais apresentadas por cada sociedade, bem como seu peculiar sistema moral.

Essa concepção de cultura revela um complexo de valores adotados por um grupo específico, que se confunde com sua própria identidade. Segundo Taylor (2009, p. 48), a identidade "é o que define quem somos e de onde viemos", ela precede o surgimento do "ser" e o absorve. Além de se constituírem como um conjunto de valores, essas "culturas societárias" também dão origem a um conjunto de instituições específicas. Por esse motivo, é possível dizer que todas as democracias ocidentais compartilham uma cultura comum, uma civilização moderna, urbana, secular e industrializada.

Pode-se afirmar que a sociedade ocidental é também expressão de uma cultura liberal cujos pilares éticos repousam no individualismo, neutralidade, primazia da razão instrumental e garantia de direitos de liberdade e igualdade formais. Para Kahn (2001), o Estado de Direito é uma cultura como todas as outras: tem suas crenças inafastáveis, suas razões e suas próprias normas.

Ainda segundo Kahn (2001), o pluralismo cultural é um dos maiores problemas enfrentados pelo liberalismo, tendo em vista que este não defende a existência de uma verdade absoluta em relação às crenças, conduzindo, pois, ao problema de como lidar com aqueles que vivem de acordo com normas diferentes, inclusive antiliberais.

A grande questão aponta quando essa sociedade ocidental se arvora como o padrão civilizatório e nega a existência de outras formas societárias que se mantém estáveis no tempo e cultivam uma "civilidade 
pacífica", sem ter de apelar para o individualismo ou politicas de direitos individuais.

Como adotar o padrão da igualdade ocidental e querer fazer valer a "integridade de direitos humanos" sem que para tanto se pratique uma violação dos mesmos? Boaventura de Souza Santos (2003, p. 27) expõe o problema que confronta prática e discurso no que se refere aos direitos humanos:

Se observarmos a história dos direitos humanos no período imediatamente a seguir à Segunda Grande Guerra, não é difícil concluir que as políticas de direitos humanos estiveram em geral a serviço dos interesses econômicos e geopolíticos dos Estados capitalistas hegemônicos. Um discurso generoso e sedutor sobre direitos humanos coexistiu com atrocidades indescritíveis, que foram avaliadas com revoltante duplicidade de critérios. Escrevendo em 1981 sobre a manipulação temática dos direitos humanos nos Estados Unidos pelos meios de comunicação social, Richard Falk identifica uma 'política de invisibilidade' e uma 'política de supervisibilidade'. Como exemplos da política de invisibilidade menciona Falk a ocultação total pela mídia das notícias sobre o trágico genocídio do povo Maubere em Timor Leste (que ceifou mais de 300 mil vidas) (...). A verdade é que o mesmo pode dizer-se dos países da União Europeia, sendo o exemplo mais gritante justamente o silêncio mantido sobre o genocídio do povo Maubere, escondido dos europeus durante uma década, assim facilitando o contínuo e próspero comércio com a Indonésia.

Afastando-se da proposição teleológica de Norberto Bobbio, Douzinas (2000, p. 20) resume: "Se o século XX é a era dos direitos humanos, seu trunfo é, no mínimo, um paradoxo. Nossa época tem testemunhado mais violações de seus princípios do que uma das épocas anteriores e menos 'iluminadas'." A ascensão de um sentido normativo qualquer ou de um tipo de ideologia central nas sociedades não pode ser um encantamento sem sentido crítico e respeito às diferenças culturais. A louva-deus faminta devora seu esposo para garantir a sobrevivência da espécie. Os direitos no contexto de domínio norte-ocidental não 
podem ser encarados como necessidade imperiosa a devorar nossa inteligência para satisfazer a sobrevivência dos seus. O discurso de direitos humanos não pode ser um instrumento a atender acriticamente à Europa e Estados Unidos no seu poder de impor sanções e ignorar o diálogo internacional.

\section{A mutilação genital feminina (MGF)}

Órgãos como aAnistia Internacional afirmam que aproximadamente 135 milhões de garotas no mundo já se submeteram à mutilação genital e 2 milhões de garotas por ano estão em risco de sofrê-la (AMNESTY INTERNATIONAL, 2014, online). Esse é um dado provavelmente coletado de forma primeira pela Organização Mundial de Saúde, que informava no impresso Female Genital Mutilation - A Student's Manual, em 2001, que de 100 a 140 milhões de garotas e mulheres sofreram alguma mutilação ((WORLD HEALTH ORGANIZATION, 2014, on line). A mutilação é prática corrente em mulheres africanas há mais de três mil anos e também está inserida na cultura de países árabes e islâmicos, bem como no continente asiático, ainda que em menor proporção. Em 1993, a Associação Médica Mundial definia (WORLD HEALTH ORGANIZATION, 2014, on line):

Há várias formas de MGF. Pode ser uma circuncisão primária em garotas, normalmente entre 5 e 12 anos de idade, ou uma circuncisão secundária, e.g., após o nascimento. A extensão da circuncisão primária pode variar: de uma incisão no prepúcio do clitóris até uma circuncisão faraônica ou infibulação removendo o clitóris e os pequenos lábios além da costura dos grandes lábios de forma que somente uma abertura mínima permanece para permitir a urina e o fluxo menstrual.

A chamada "circuncisão feminina", excisão ou infibulação, denominada na literatura médica como "mutilação genital feminina" (MGF), tem diferentes níveis de mutilação, incluindo a extirpação do clitóris, pequenos e grandes lábios ou retirada da genitália por 
completo, deixando apenas um orifício deformado para fluir a urina e a menstruação. Nussbaum (2013, p. 341) descreve a existência de três tipos distintos de corte:

1) Na clitoridectomia, uma parte ou a totalidade do clitóris é amputada e a hemorragia é estancada por pressão ou ponto de sutura; 2) Na extirpação, o clitóris e os pequenos lábios são amputados; 3) Na infibulação, o clitóris é removido, parte ou a totalidade dos pequenos lábios é cortada, e são feitas incisões nos grandes lábios para criar área cruenta.

O manual da OMS, aqui utilizado como fonte de análise informativa das campanhas de educação da organização, descreve de forma sistemática as partes que podem ser mutiladas. A mais superficial é o tipo I, que implica na excisão das dobras de pele que envolvem o clitóris até sua própria ponta. O tipo II se estende até os lábios pequenos. O tipo III consiste na retirada da genitália feminina, incluindo os grandes lábios com costura e o estreitamento da abertura vaginal, de forma que ela possa transparecer apenas um orifício mutilado, sem genitália externa. Esta última é a definição própria da infibulação. O tipo IV considerado pelo mencionado manual traduz toda forma de incisão ou cauterização do clitóris e tecidos circundantes, raspagem ou cortes vaginais, além da introdução de ervas ou substância corrosivas visando fazê-la sangrar ou provocar estreitamento da abertura vaginal.

Pela expansão da prática cultural, um número ilimitado de fontes traz o testemunho dessa prática, sendo possível acessar fotos, vídeos e depoimentos chocantes diante dos princípios de proteção à criança, à pessoa humana e ao direito à dignidade corporal.

Tomando por exemplo a cultura bantu (KIMBANDA, 2006), em Angola, essa prática se desenvolve de modo natural, associada a um referencial sociológico, de ascensão da mulher à vida organizacional da tribo, como indicativo de maturidade, e como condição ao casamento para o homem. Para tanto, as mulheres entre 7 a 13 anos são encaminhadas pelos próprios pais à realização de tal excisão. A faixa 
etária considerada no estudo de Kimbanda não pode ser generalizada, pois há uma multiplicidade de práticas em outras regiões do globo onde se pratica este tipo de hábito cultural mutilador. Em geral, os homens africanos da cultura bantu se recusam a casar com mulheres não mutiladas. Dentre os vários motivos, a crença da presença do clitóris as deixariam mais "fogosas", e por consequência, mais aptas à infidelidade, e, por outro lado, a sua ausência, aumenta o prazer do homem. Exsurge também como argumentos a ideia de que o clitóris seria uma miniatura do órgão sexual masculino, e de que as mulheres que não o retirassem não teriam filhos homens ou os mesmos nasceriam anormais, pois elas seriam consideradas "impuras".

As justificativas se estendem a tal ponto que alcançam as próprias mulheres, que são conduzidas resignadamente por aceitarem como "normal" e não entenderem, naquele momento, a castração como violação de direitos humanos.

Aquestão encontra-se, portanto, entre dois prismas diametralmente distintos. O primeiro, inserido na esfera do multiculturalismo, pressupõe um pluralismo étnico, religioso e cultural que traz ínsita a ideia de identidade do indivíduo ao grupo de pertencimento e, portanto, a ótica universalista não poderia se imiscuir.

Por outro lado, a mutilação genital feminina está colocada como prática de tortura no cenário mundial pós-DUDH, que, em seu art. $5^{\circ}$, define que ninguém será submetido à tortura ou tratamento desumano ou degradante. No âmbito da Europa, a MGF é praticada de forma clandestina e se advoga ali a aplicação das leis contra a tortura. AAnistia Internacional da Irlanda relata que casos judiciais na França dão conta de indícios da prática secreta de MGF em alguns países europeus, mas não há evidências da intensidade dessa tortura. O mais provável é que crianças e garotas sejam levadas para seus países de origem durante as férias e lá chegam a sofrer as mutilações, impostas como obrigações da cultura do seu povo (FGM..., 2014, on line).

Ainda de acordo com matéria da Anistia Internacional anteriormente mencionada, na maioria das vezes, é necessário um corte vaginal para 
que ocorra primeira relação sexual das garotas (AI INDEX, 2014, on line).. "Em um estudo realizado no Sudão, 15\% das mulheres entrevistadas relataram que cortar foi necessário antes que a penetração pudesse ocorrer"(AI INDEX, 2014, on line). Além disso, após o nascimento das crianças, as mulheres são novamente reinfibuladas. Esses constantes cortes na genitália feminina provocam feridas de difícil cicatrização.

A Declaração de Budapeste, adotada pela 45a Assembleia Geral da Associação Médica Mundial em Budapeste, Hungria (WMA, 1993), tratando especificamente sobre a mutilação genital feminina, em seu preâmbulo, alerta categoricamente sobre suas consequências danosas para a saúde da mulher:

Independentemente da extensão da circuncisão, a MGF afeta a saúde de mulheres e meninas. Evidências científicas demonstram os graves danos permanentes à saúde. As complicações agudas decorrentes da MGF são: hemorragia, infecções, sangramento de órgãos adjacentes, dor excruciante. As complicações no longo prazo incluem cicatrizes graves, infecções crônicas, complicações tanto obstétricas quanto urológica, por fim problemas psicológicos e sociais. FGM tem consequências graves para a sexualidade e a forma como ela é vivida. Há uma multiplicidade de complicações durante o parto, incluindo perturbações na expulsão, formação de fístulas, roturas e incontinência.

Diz ainda a Associação Médica Mundial: "Em muitos outros países, o problema surgiu mais recentemente, devido à presença de grupos étnicos de países nos quais a MGF é uma prática comum, incluindo imigrantes e refugiados que fugiram da fome e da guerra" (WMA, 1993). Os médicos têm participado dessas circuncisões por razões de mal menor, frente à impotência em combater a prática: "Médicos em todo o globo deparam-se com os efeitos desta prática tradicional. Às vezes, eles são chamados a realizar aquele procedimento mutilador" (WMA, 1993).

Entretanto, os maiores males de sequelas de saúde decorrem, em grande parte, em virtude das condições em que a extirpação da genitália 
é praticada. Instrumentos não apropriados, como giletes e cacos de vidro sem qualquer esterilização e cuidado, são usados pelas chamadas excisadoras - mulheres que desempenham essa função, gozando de prestígio pela sua comunidade - e realizam o procedimento doloroso e arriscado, que pode vitimar essas mulheres ou, no mínimo, deixarem marcas indeléveis e irreversíveis ${ }^{7}$.

É certo que o sentimento de pertença a uma determinada cultura pode ser preponderante no momento em que os pais decidem submeter seus filhos à circuncisão. Isso é possível de se vislumbrar no depoimento de uma mulher egípcia, ao falar de suas filhas menores: "É claro que eu devo circuncidá-las, exatamente como seus pais, suas avós e irmãs foram circuncisadas. Isto é nosso costume."8 Mas será que, caso fosse possível educá-las de forma a entenderem que existem opções além daquela oferecida pelo seu meio, ainda assim optariam pela mutilação?

A criança não é capaz de escolher pelo corte genital, visto que sequer possui maturidade para isso, cabendo à sua mãe, como responsável, assim optar. A mãe ou não percebe como violento o procedimento tradicional, ou ela o encara a partir de tabus que fazem crer que ele é necessário, ficando culturalmente coagida a pelo menos tolerar e permitir o rito. É a ausência de escolha no plano da tópica de uma cultura.

Isso parte de um pressuposto básico: educação. Enquanto nos Estados Unidos a alfabetização dos adultos é de 99\% para homens e mulheres, no Togo, a alfabetização feminina adulta é de $32,9 \%$, e a

Muitas meninas fogem e são assim mal vistas pela sociedade. A trajetória de vida de Waris Dirie é retratada pelo filme Flor do Deserto, de Sherry Hormann, 2010. Trata-se uma somali que sofreu mutilação genital quando criança e se refugiou em Londres, sendo hoje embaixadora especial da ONU para combater esse costume africano. Flor do deserto. Direção: Sherry Normann. Reino Unido, Áustria e Alemanha, 2009. O filme tem base no best seller "The desert flower", de Waris Dirie e Cathleen Muller.

8 Tradução livre para "Of course I shall have them circumcised exactly as their parents, grandparents and sisters were circumcised. This is our custom". Em Assaad, M.B., "Female Circumcision in Egypt: Social Implications, Current Research and Prospects for Change", Studies in Family Planning, 11:1, 1980, p. 3-16, citado em Anistia Internacional. (AMNESTY INTERNATIONAL, 2014, on line). 
masculina, 52\%. Na Costa do Marfim, o percentual atinge $26,1 \%$ e 56\%, respectivamente, entre mulheres e homens (NUSSBAUM, 2013). Esse fato compromete a maturidade das decisões, as quais, em sua maioria, são tomadas sem qualquer reflexão sobre o tema. Nesses termos, conclui Naussbaum (2013, p. 347):

O analfabetismo é um obstáculo à independência; outros obstáculos são introduzidos pela dependência econômica e a falta de oportunidades de emprego. Esses fatos sugerem limites às noções de consentimento e escolha, mesmo quando aplicados às mães ou parentes que realizam a operação.

Muitas são as campanhas para erradicar a prática na África, por exemplo. As ações de combate a tal prática popular podem ser concebidas como enfrentamento e condenação cultural, como igualmente podem ser empreendidas com esclarecimento e diálogo intercultural, visando condenar firmemente a prática sem decretar guerra cultural.

\section{0 diálogo intercultural e a hermenêutica diatópica}

As mulheres africanas que são submetidas - ainda meninas - a essas práticas o fazem ingenuamente, mas sofrem as consequências nefastas em sua saúde física e mental por toda uma vida.

O problema voltado ao reconhecimento das particularidades culturais de uma sociedade inicia-se quando presente a violação à dignidade humana, corolário dos direitos humanos e valor intrínseco à condição de "ser" humano.

Na esteira do universalismo, busca-se assegurar uma uniformidade na aplicação dos direitos e liberdades fundamentais, na medida em que se toma por paradigma a dignidade humana como eixo de proteção e nenhuma cultura poderia se sobrepor a tal valor geral.

Os direitos internacionais de direitos humanos são, em sua essência, universalistas, visto que asseguram a proteção universal dos direitos e liberdades fundamentais. Bonavides (2006, p. 562) afirma 
que "a vinculação essencial dos direitos fundamentais à liberdade e à dignidade humana, enquanto valores históricos e filosóficos, nos conduzirá sem óbices ao significado de universalidade inerente a esses direitos como ideal da pessoa humana".

Perceba-se que a Declaração de Viena, em seu $\S 5^{\circ}$, orienta o posicionamento dos Estados nesse conflito com realidades locais:

Todos os direitos humanos são universais, indivisíveis, interdependentes e inter-relacionados. A comunidade internacional deve tratar os direitos humanos globalmente, de maneira justa e unânime, com os mesmos parâmetros e com a mesma ênfase. As peculiaridades nacionais e regionais e bases históricas, culturais e religiosas devem ser consideradas, mas é obrigação dos Estados, independentemente de seu sistema político, econômico e cultural, promover e proteger todos os direitos humanos e liberdades fundamentais.

O Estado liberal e democrático é fruto da tradição e da história, e essa condição está refletida nas suas instituições e em seu ordenamento jurídico. O liberalismo, portanto, assenta seus pilares no individualismo, no neutralismo e nos direitos fundamentais, sendo constantemente desafiado pelas culturas antiliberais que buscam expressar suas identidades particulares.

Como se refere Gondim (2011, p. 9), “o Estado liberal só tem duas saídas: ou ele se torna efetivamente neutro, o que é impossível tendo em vista a sua condição histórica, ou ele assume seu modo de vida, assume sua concepção restrita do bem, e procura meios para ser mais inclusivo".

As potências hegemônicas apresentam o direito humanitário como um imperativo moral para a comunidade internacional, e com base nisso afastam os princípios da soberania estatal e não intervenção. 0 Direito, enquanto manifestação da moral da sociedade, também se situa na diversidade sociocultural, não sendo neutro. São os valores mais caros a cada sociedade que culminam por se introduzir na ótica de suas garantias fundamentais. 
Uma opinião possível consiste em defender a posição de um relativismo cultural fraco ou universalismo forte, que permitiria desvios de normas de direitos humanos internacionais no nível da forma, ou da implementação. Silva (2010, p. 83) defende essa teoria, também denominada de universalismo cultural como uma forma de proteger os mais variados povos das atrocidades cometidas em nome das manifestações culturais e dos direitos fundamentais desses Estados. Bonavides (1993, p. 482) igualmente chancela essa posição:

A nova universalidade procura, enfim subjetivar de forma concreta e positiva os direitos da tríplice geração na titularidade de um indivíduo que antes de ser o homem deste ou daquele país, de uma sociedade desenvolvida ou subdesenvolvida, é pela sua condição de pessoa um ente qualificado por sua pertinência ao gênero humano, objeto daquela universalidade.

Como opina Gondim (2011), a tolerância e a democracia são conceitos interdependentes. Isso porque a democracia tem como premissa a existência de certo grau mínimo de pluralismo, que só pode existir, e ser mantido de maneira pacífica, através do exercício da tolerância.

Todo esse arcabouço teórico, porém, gera um perigo concreto: interpretar o conteúdo, a justeza e correção na prática da "proteção" aos direitos humanos, sem que isso se configure em um direito de ingerência ou "guerra preventiva" (PUREZA, 2014), situando o Direito internacional público entre duas questões: a soberania das nações e a legitimidade de intervenções externas em razão de princípios humanitários.

Ao mesmo tempo em que a cultura não pode ser utilizada como "carta branca" para justificar práticas violadoras à dignidade da pessoa humana, também não se pode obrigar determinados povos a alterarem suas manifestações culturais porque ratificaram acordos internacionais sobre a matéria. O equilíbrio e o diálogo intercultural devem ser buscados incessantemente. 
Santos (2013), ao enfrentar o tema, propõe uma hermenêutica diatópica como método para reconceitualizar os direitos humanos num projeto cosmopolita. Não se trata de renunciar aos valores e proposições dos direitos humanos nem de querer simular ser partícipe de outra cultura.

Este estudo não deseja ser uma reprodução acrítica e obediente das teorias com as quais dialoga. Dentre as premissas utilizadas aqui, anotam-se: a superação do debate entre universalismo e relativismo, cujos conceitos polares são prejudiciais para uma concepção emancipatória de direitos humanos.

\begin{abstract}
"Todas as culturas são relativas, mas o relativismo cultural enquanto atitude filosófica é incorreto". [...] "Todas as culturas aspiram a preocupações e valores universais, mas o universalismo cultural, enquanto atitude filosófica, é incorreto". [...] "Todas as culturas são incompletas e problemáticas nas suas concepções de dignidade humana". [...] "A incompletude provém da própria existência de uma pluralidade de culturas, pois, se cada cultura fosse tão completa como se julga, existiria apenas uma só cultura. Aumentar a consciência de incompletude cultural até ao seu máximo possível é uma das tarefas mais cruciais para a construção de uma concepção multicultural de direitos humanos". (SANTOS, 2014)
\end{abstract}

A hermenêutica diatópica parte do princípio de que não se deve analisar uma cultura a partir dos topoi de outra. O seu objetivo não é atingir a completude, mas ampliar ao máximo a consciência de incompletude mútua através do diálogo. Isso implica em renunciar à ideia de intervenção pelos direitos humanos em favor de um diálogo pelos direitos humanos, mas não significa o relativismo inerte, nem a omissão; nem mesmo significaria que um brasileiro deixaria de operar com seus próprios valores para ser um indiano, ou um angolano, como se o background cultural pudesse ser vestido a qualquer conveniência.

Em seu artigo, Santos (2014) aborda como bom exemplo de hermenêutica diatópica o dado por Adbullahi Anna-im, entre a cultura 
islâmica e a cultura ocidental no campo dos direitos humanos. Existe um longo debate entre o islamismo e direitos humanos. Muitos desses debates têm como fundamento a posição fundamentalista, pela qual o sistema jurídico religioso do Islã, a Sharia, deve ser integralmente aplicado como direito do Estado Islâmico. Segundo essa posição, em caso de conflito com direitos humanos, a Sharia deve prevalecer. Isso sói ocorrer principalmente em relação às mulheres, cuja igualdade sequer é tratada pela Sharia. A elas, é vedada qualquer forma de vida pública, cabendo-lhes a segregação.

Em outro extremo, a posição dos secularistas entende que o Islã é um movimento religioso e espiritual, não político. Destarte, a aceitação de direitos humanos internacionais é questão de decisão política, não religiosa.

Anna-im critica essas duas posições extremas e propõe encontrar fundamentos interculturais que aproximem os dois sistemas. Para se chegar a um consenso, é necessária uma reforma islâmica, assentada numa revisão evolucionista das suas fontes, cujo contexto histórico de criação foi o dos juristas dos séculos VIII e IX, quando a ideia restritiva era justificada. Hoje, porém, seria possível reencontrar nas fontes originárias do Islão plena justificação para uma visão mais ampla de reciprocidade, e ensina:

A mensagem primitiva de Meca é a mensagem eterna e fundamental do Islão, que sublinha a dignidade inerente a todos os seres humanos, independentemente de sexo, religião ou raça. Esta mensagem, considerada demasiado avançada para as condições históricas do século VII (a fase de Medina), foi suspensa e a sua aplicação adiada até que no futuro as circunstâncias a tornassem possível. O tempo e o contexto, diz An-na'im, estão agora maduros para tal.

Nesse caso, seria possível buscar justificar uma evolução cultural tomando por base as próprias fontes históricas do Islã, sem descaracterizar o povo, sem submissão a qualquer outra forma de dominação. Santos (2014) enxerga como promissora a abordagem de 
Anna-im, tendo em vista que, dentro da ideia da hermenêutica diatópica, transforma a concepção de direitos humanos ocidental numa concepção intercultural que reivindica para eles a legitimidade islâmica, em vez de renunciar a ela.

Por fim, dois imperativos interculturais são propostos para todos os grupos empenhados na hermenêutica diatópica. Primeiro: das diferentes versões de uma dada cultura, deve prevalecer aquela que represente o círculo mais amplo de reciprocidade, ou seja, aquela que representaria o máximo divisor comum, aquele que alcança o reconhecimento do outro; o segundo imperativo orienta no sentido de que "as pessoas e os grupos sociais têm o direito a ser iguais quando a diferença os inferioriza, e o direito a ser diferentes quando a igualdade os descaracteriza".

Dessa forma, a aceitação das incompletudes de cada cultura, a partir de uma noção dos topoi alheio, pode ser a alternativa mais pacifista para que o diálogo intercultural se desgarre da submissão a uma ditadura de direitos humanos universalizantes, mas preserve a dignidade da pessoa humana. Vejamos que "noção" não é renúncia cultural, nem é imersão acrítica ou artificial em outra cultura. Falamos sempre a partir de um referencial cultural próprio, mas o respeito pelo outro é perfeitamente viável num propósito dialético. Por mais que a pessoa de um português venha a compreender os topoi da cultura brasileira, ele será sempre alguém que aprendeu conosco. A recíproca é verdadeira e a diatópica interpretativa é uma referência importante como pressuposto de práticas educativas consequentes.

Diferentemente do diálogo, as nações podem argumentar em favor dos direitos humanos para promover a coação, a intervenção e a guerra. Não se iguala a menção aos direitos humanos por um ativista africano com a argumentação fundada nos direitos humanos por um partidário do GOP nos Estados Unidos. A melhor expressão do diálogo nos casos de MGF está no ativismo educativo dos grupos de direitos humanos em diferentes países que combatem a prática étnica com cultura em favor da autonomia e da proteção a crianças e mulheres, para que não mais sejam vítimas do tabu de seus antepassados. Diálogo é complexidade. 


\section{Conclusão}

A dificuldade na concretização dos direitos humanos está na forma como cada Estado atua ao positivá-los na sua ordem interna. A depender do contexto sociológico e cultural, vê-se assimilar no campo jurídico suas próprias definições e conteúdo acerca da sua representação de direitos humanos. Essa positivação fria, justificada na ética e moral de sua própria comunidade, calcada na tradição e costumes, por vezes se desgarra do objetivo essencial de proteger o "humano" desses direitos.

A DUDH, em seu objetivo histórico, alargou o conceito de direitos humanos para o mundo e, em que pese a ausência de força normativa, representou um marco jurídico na positivação dos mesmos e assim exigiu o seu respeito. Nesse contexto, quanto maior a adesão ao conceito universalista de direitos humanos, maior a proteção à vida humana no pós-guerra, marcado por intolerâncias étnicas, religiosas e políticas. Passado esse momento, a conjuntura reflete uma maior visibilidade das minorias e de seus costumes, as quais hoje requerem sua inserção e respeito à identidade das mesmas, razão pela qual, o relativismo também ganhou seu espaço.

Contudo, por esse sistema, penas capitais, punições corporais, mutilação feminina e clitorectomia são frequentes e aceitas por determinados povos que vislumbram tais manifestações como necessárias, atrelado aos seus costumes, legitimados pela ordem jurídica interna.

$\mathrm{O}$ direito à vida digna é universal. Tal assertiva é propositiva. A questão que se coloca é: quais os limites para a violação da vida de uma pessoa? A afirmação do caráter universal dos direitos humanos pretende um parâmetro mínimo para as relações sociais. Os direitos humanos na perspectiva do dialogo intercultural e através da hermenêutica diatópica podem aproximar as culturas naquilo que as distingue de modo a promover uma cidadania multicultural, minimizando as exclusões, mas, sobretudo, respeitando-se o valor essencial ao ser humano, a vida. 


\section{Referências}

AMNESTY INTERNATIONAL. What is female genital mutilation? Disponível em: <http://www.amnesty.org/en/library/asset/ ACT77/006/1997/en/373c3381-e984-11dd-8224-a709898295f2/ act770061997en.pdf>. Acesso em: 15 mar. 2014.

ARENDT, Hannah. As origens do totalitarismo. Tradução de Roberto Raposo. Rio de Janeiro. Documentário, 1979.

BOBBIO, Norberto. A era dos direitos. Tradução de Carlos Nelson Coutinho. Rio de Janeiro: Editora Campus, 1992.

BONAVIDES, Paulo. Curso de Direito Constitucional. 4. ed. São Paulo. Malheiros, 1993.

CANOTILHO, José Joaquim Gomes. Direito Constitucional e teoria da constituição. Coimbra: Almedina, 2003.

COMPARATO, Fábio Konder. A afirmação histórica dos direitos humanos. 5. ed. São Paulo: Saraiva, 2007.

COSTA, Leonardo Gadelha. Liberdade e escravidão na prática judicial das províncias: um estudo sobre as ações de liberdade no Ceará. 2010. 248 f. Dissertação (Mestrado em Direito Constitucional) Universidade de Fortaleza, 2010.

DOUZINAS, Costas. 0 fim dos direitos humanos. São Leopoldo: Unisinos, 2000.

ESPIELL, Hectos Gros. Los derechos económicos, sociales y culturales en el sistema interamericano. San José: Libro Libre, 1986.

FEITOSA, Maria Luiza P. de A. M. O currículo de direitos humanos no ensino superior e na Pós-Graduação. Espaço do Currículo, Paraíba, v. 2, n. 2, p. 98-114, set. 2008-mar. 2009.

FLORES, Joaquín Herrera. A reinvenção dos direitos humanos. Florianópolis: Fundação Boiteux, 2009. 
FRANCE. Assemblée Nationale. Constitution de 1791. Disponível em: $<$ http://www.assemblee-nationale.fr/histoire/constitutions/constitutionde-1791.asp>. Acesso em: 12 maio 2014.

GONDIM, Larissa Cristine Daniel. Multiculturalismo e direitos humanos: a politica da tolerância em face dos direitos de grupos culturais. 2011. 153 f. Dissertação (Mestrado em Direito) - Centro de Ciências Jurídicas, Universidade Federal da Paraíba, Joao Pessoa, 2011.

GOUGES, Olympe. Déclaration des Droits de la Femme et de la Citoyenne. In: FRANCE. Assemblée Nationale, 1791. Disponível em: <http://www.assemblee-nationale.fr/histoire/femmes/olympe-degouges_declaration-des-droits-de-la-femme.asp>. Acesso em: 12 maio 2014.

HOBSBAWM, Eric. A revolução francesa. Rio: Paz e Terra, 1996.

KAHN, Paul. El analisis cultural del derecho: uma reconstruccion de los estúdios jurídicos. Barcelona: Gedisa, 2001.

KÄLIN, Walter; KÜNZLI, Jörg. The law of international human rights protection. New York: Oxford University Press, 2010.

KIMBANDA, Rufino Waway. Excisão como Iniciação Sexual e Religiosa em Mulheres Negro-Bantu. Revistas de Estudos da Religião, São Paulo, n. 1, 2006. Disponível em: <http://www.pucsp.br/rever/ rv1_2006/t_kimbanda.htm>. Acesso: 09 maio 2014.

LAFER, Celso. Comércio, desarmamento, direitos humanos: reflexões sobre uma experiência diplomática. São Paulo: Paz e Terra, 1999.

LUCENA, Rosana Batista de. Aborto, direitos humanos e desigualdade de gênero no Brasil. João Pessoa: UFPB, 2008.

MAGALHÃES, José Luiz Quadros. Princípios Universais de direitos humanos e o novo Estado democrático de direito. Jus Navegandi, Teresina, ano 1, n. 12, maio, 1997. Disponível em http://jus2uol.com.br/ doutrina/texto.asp?id=74 
NUSSBAUM, Martha C. Julgando outras culturas: o caso da mutilação genital. In: Biroli, Flávia e Miguel, Luis Felipe. Teoria política feminista: textos centrais. Vinhedo: Editora Horizonte, 2013. p. 339-358.

PAES, Mariana Armond Dias. O estatuto jurídico dos escravos na civilística brasileira. 2010. Monografia (Bacharelado em Direito) Universidade Federal de Minas Gerais, Belo Horizonte, 2010.

PIOVESAN, Flávia. Direitos humanos e o direito constitucional internacional. 4. ed. São Paulo: Max Limonad, 2008.

PIOVESAN, Flávia. Temas de direitos humanos. 5. ed. São Paulo: Saraiva, 2012.

PUREZA, José Manuel. Anarquia ou direito. Disponível em: <http:// www.ces.fe.uc.pt/nucleos/nep/comunicacoes001.php>. Acesso em: 13 fev. 2015.

RÚBIO, David S.; FLORES, Joaquín Herrera; CARVALHO, Salo de. (Orgs.) Direitos Humanos e globalização: fundamentos e possibilidades desde a teoria crítica. 2. ed. Porto Alegre: EDIPUCRS, 2010. Disponível em: <http://www.pucrs.br/edipucrs/direitoshumanos. pdf>. Acesso em: 13 fev. 2015.

SANTOS, Boaventura de Souza. As tensões da modernidade. Disponível em: <http://www.dhnet.org.br/direitos/militantes/boaventura/ boaventura4.html>. Acesso em: 10 mar. 2014.

- Por uma concepção multicultural de direitos humanos. In: SANTOS, Boaventura. Reconhecer para libertar: os caminhos do cosmopolitismo multicultural. Rio de Janeiro: Civilização Brasileira, 2003. p. 427-462.

SANTOS, Martha Sofia. Cleansing Honor with Blood: Masculinity, Violence, and Power in the Backlands of Northeast Brazil, 1845-1889. Stanford, California: Stanford University Press, 2012.

SILVA, Carla Ribeiro Volpini. O Universalismo e o relativismo cultural: impasse entre a efetivação dos direitos humanos internacionais e as praticas culturais permitidas pelos direitos fundamentais, mas 
abominadas pelo resto do mundo. In: ALMEIDA, Gregrório Assagra de et al. Direitos fundamentais e sua proteção nos planos interno e internacional. Belo Horizonte: Arraes Editores. 2010, p. 138-169.

TAYLOR, Charles. A ética da autenticidade. Tradução de Luís Lóia. São Paulo: Edições 70, 2009.

UNGER, Mangabeira. O direito na sociedade moderna. Rio de Janeiro: Civilização Brasileira, 1979.

WORLD MEDICAL ASSOCIATION. Statement on Female Genital Mutilation 1993. Disponível em: <http://www.wma.net/ en/30publications/10policies/c10/>. Acesso em: 17 jul. 2014.

ZINN, Howard. A People's History of the United States. New York: Harper Perennial Modern Classics, 2005.

Recebido em: 02/08/2014

Aprovado em: 20/11/2014 